\title{
Simultaneous HPLC Determination of Lidocaine Hydrochloride and Hexachlorophene in a Suppository Product
}

\author{
Cece Furwanti ${ }^{1}$, Kusuma Hendrajaya ${ }^{2}$, and Gunawan Indrayanto ${ }^{1}$ \\ ${ }^{1}$ Graduate Program, Faculty of Pharmacy, University of Surabaya, Surabaya, Indonesia \\ ${ }^{2}$ Pharmaceutical Chemistry Department, Faculty of Pharmacy, University of Surabaya, Surabaya, Indonesia \\ Coressepondence: Cece Furwanti \\ Email: cecefurwanti@yahoo.com
}

Submitted : 03-12-2019, Revised : 06-01-2020, Accepted : 31-05-2020

\begin{abstract}
Antihemoroid ${ }^{\circledR}$ suppository has been produced commercially by PT. Kimia Farma, Indonesia. For QC purposes, a separated densitometric method for analysis of its active ingredients, lidocaine hydrochloride and hexachlorophene, was applied. The objective of this study was obtaining more efficient analysis method of $\mathrm{LH}$ and HC, therefore an HPLC procedure has been developed for the determination of both compounds simultaneously. AYMC-Triart C18 column was used with a gradient mobile phase consisting of acetonitrile and phosphate buffer $0.05 \mathrm{M}$ (pH 6.0). Quantitative evaluation was performed at $220 \mathrm{~nm}$. Method validation was performed according to the new methods of USP 41. Result showed that the HPLC method was simple, accurate, precise, and robust. The HPLC method can be applied in simultaneous determination of $\mathrm{LH}$ and HC in suppositories as a QC tool in the pharmaceutical industries.
\end{abstract}

Keywords: hexachlorophene; HPLC; lidocaine HCl; method validation; suppository 


\section{Introduction}

PT. Kimia Farma (Persero) Tbk., Plant Watudakon, Jombang, Indonesia, produced antihemoroid ${ }^{\circledR}$ suppository which have indication as anti-hemorrhoids; the active ingredients were lidocaine $\mathrm{HCl}(\mathrm{LH})$, hexachlorophene (HC), bismuth subgallate and zinc oxide; the registration number of antihemoroid ${ }^{\circledR}$ was GKL1732302453A1 [1].

Presently, a separated densitometric methods for analyzing of LH and HC were applied for the QC purposes at PT. Kimia Farma, Indonesia. Stojanovicet al. [2] reported simultaneously determination of LH and hydrocortisone in suppositories by HPLC. Method of analysis of mixtures $\mathrm{LH}$, dexamethasone acetate, calciumdobesilate, butyl hydroxy anisole, and degradation product of hydroquinone in suppositories and ointment by HPLC were also reported [3]. Analysis of mixtures of LH, betamethasone valerate, and phenylephrine in suppositories by HPLC was also described [4]. Determination of LH with other active pharmaceutical ingredient (API) in injections and mouthwash were also published previously [5-6]. Gagliardi et al. [7] reported the analysis of mixtures of $\mathrm{HC}$ and other preservatives in cosmetic preparations by HPLC.

There is no official method of simultaneous determination for both LH and HC in Indonesian Pharmacopeia V [8] and United States Pharmacopoeia 41 [9]. Unfortunately, no publications reported simultaneous assay of LH and HC in pharmaceutical preparations including suppositories by HPLC. The objective of this present work is to develop a valid and simple HPLC method, that can be applied for analyzing LH and HC simultaneously in suppositories. The proposed HPLC method was validated according to the new guidance of USP 41 [10-13].

\section{Materials and methods}

\subsection{Materials and chemicals}

LH (Apex Healthcare Limited, Gujarat, India),
HC (Tokyo Chemical Industry, Tokyo, Japan), bismuth subgallate (Anmol Chemicals, Gujarat, India), zinc oxide (PT. Indoxide Surabaya, Indonesia), polyethylene glycol (Clariant, Bern, Swiss), glycerol (IOI Oleochemical, Penang, Malaysia), subanal EF-37 and sub anal EF- 42 (Dott. Bonapace \& C, Via Salerno, Italy), white petrolatum (Rose Polymer Co., Ltd., Tehran, Iran), castor oil (Thai Castor Oil Industries, Co., Ltd., Bangkok, Thailand); all of pharmaceutical grade substances were used directly for preparation of laboratory-made (LM) suppositories and standard solutions. Other chemicals were acetonitrile HPLC grade (Merck, Darmstadt, Germany), methanol HPLC grade (Merck, Darmstadt, Germany), disodium hydrogen phosphate dehydrates for analysis (Merck, Darmstadt, Germany), orthophosphoric acid 85\% analytical grade (Merck, Darmstadt, Germany).

\subsection{Preparation of laboratory-made (LM) sup- positories}

The composition (weight \%) of suppository according to the claim label was bismuth subgallate $6 \%$, zinc oxide $7.5 \%$, LH $0.5 \%$ and HC $0.125 \%$, polyethylene glycol $0.93 \%$, glycerol $3.2 \%$, subanal EF-37 23.08\%, subanal EF-42 $37.43 \%$, white petrolatum $18.15 \%$, castor oil $3.0 \%$. All excipients were weighed and melted at $60^{\circ} \mathrm{C}$ into homogeneous mixture, $\mathrm{LH}$ and $\mathrm{HC}$ were added, and then formed into suppository and cooled in a refrigerator at $-18^{\circ} \mathrm{C}$. The weight of $\mathrm{LM}$ suppository was $2.00 \mathrm{~g}$.

The laboratory-made (LM) suppository preparation was prepared containing three different concentration levels i.e. 80\% (LM1), $100 \%$ (LM2), and $120 \%$ (LM3) of the claim label; concentration of LH in LM1-3 were $8 \mathrm{mg}, 10 \mathrm{mg}$, and $12 \mathrm{mg}$, respectively; whereas concentration of HC in LM1-3 were $2 \mathrm{mg}, 2.5 \mathrm{mg}$, and $3 \mathrm{mg}$, respectively. These LM suppositories were used for accuracy and precision determinations.

\subsection{Preparation of standard solutions}


The stock solutions were prepared by dissolving of LH and HC (accurately weighed circa $25.000 \mathrm{mg}$ ) in 25.0 and $10.0 \mathrm{ml}$ of methanol, respectively. $2.5 \mathrm{ml}$ of the HC solution was diluted to $25.0 \mathrm{~mL}$ using methanol. The stock solutions were prepared in duplicate daily.

\subsection{LM suppositories extractions}

LM suppositories were cut into small pieces (circa $0.5 \mathrm{~cm}$ ) and a part of them were accurately weighed (circa $2.00 \mathrm{~g}$ ) and transferred into a 15.0 $\mathrm{ml}$ centrifuge tube containing $5.0 \mathrm{ml}$ of methanol then heated in a water bath at $60^{\circ} \mathrm{C}(5 \mathrm{~min})$, vortexed (1 $\mathrm{min})$, then sonicated (5 $\mathrm{min})$ and centrifuged at $4000 \mathrm{rpm}$ (10 $\mathrm{min})$. The solutions were cooled in a refrigerator at $-18^{\circ} \mathrm{C}(30 \mathrm{~min})$ and filtered by using Whatman ${ }^{\circledR}$ filter papers. The supernatants were then diluted into $10.0 \mathrm{ml}$ and the solutions were filtered through MF-Millipore membrane filter $0.45 \mu \mathrm{m}$ before injected $(10 \mu \mathrm{l})$ into an HPLC.

\subsection{HPLC instrumentation and condition}

The HPLC system used in this work was comprised of a Waters Alliance 2695 HPLC system (Massachusetts, USA) equipped with a UV/Vis detector, a binary pump, auto sampler, and column heater. The analysis was carried out on a YMC-Triart C18 column (5 $\mathrm{m}, 150$ $\mathrm{mm} \times 4.6 \mathrm{~mm}$ ) with a flow rate of $1.0 \mathrm{ml} / \mathrm{min}$. A modified gradient mobile phase from previous publications [2,7], consisted of acetonitrile and buffer solution, was utilized (Table 1). The buffer solution consisted of $0.05 \mathrm{M} \mathrm{Na}_{2} \mathrm{HPO}_{4} \cdot 2 \mathrm{H}_{2} \mathrm{O}$ and adjusted to $\mathrm{pH} 6.0$ with $85 \% \mathrm{H}_{3} \mathrm{PO}_{4}$. Detector and temperature of column heater were set at $220 \mathrm{~nm}$ and $25.0^{\circ} \mathrm{C}$, respectively. The mobile phase was prepared daily and filtered through $0.45 \mu \mathrm{m}$ and ultrasonicated for $15 \mathrm{~min}$. The chromatograms were recorded and integrated using Empower ${ }^{\mathrm{TM}} 3$ (2010) chromatographic data software (Waters).

\subsection{Method development and validation}

This proposed HPLC method was validated for selectivity, linearity, accuracy, precision, and robustness by the modified methods of USP 41 [10-13].

\subsubsection{Selectivity}

The selectivity of the method was determined by injection of standard solutions, extracts of placebo and LM2 into HPLC. Due to the lack of photodiode-array detector at PT. Kimia Farma, the purity checks of the analyte peaks were evaluated by calculating the RSD of TI (tailing factor) and total plate number $(\mathrm{N})$, which were measured at six different wave lengths according to the previous publication [14]. System suitability was evaluated according to the monograph of $\mathrm{LH}$ $[8,9]$. Stability of standards and samples were evaluated in 24 hours [14].

\subsubsection{Linearity}

For linearity study and calibrations, various standard solutions were prepared daily from the two stock solutions (60 to $150 \%$ of the expected concentrations, for LH: 600.0, 800.0, 1000.0, 1200.0, and $1500.0 \mu \mathrm{g} / \mathrm{ml}$; HC: $160.0,200.0$, $250.0,300.0$, and $360.0 \mu \mathrm{g} / \mathrm{ml}$ ), each of these so-

Table 1. Composition of gradient mobile phase $(\mathrm{v} / \mathrm{v})$

\begin{tabular}{lll}
\hline Time (minutes) & Acetonitrile (\%) & Phosphate buffer (\%) \\
\hline 0.0 & 45.0 & 55.0 \\
5.0 & 75.0 & 25.0 \\
7.0 & 85.0 & 15.0 \\
9.0 & 95.0 & 5.0 \\
11.0 & 100.0 & 0.0 \\
15.0 & 45.0 & 55.0 \\
\hline
\end{tabular}


lution $(10 \mu \mathrm{l})$ was injected into the HPLC.

\subsubsection{Accuracy and precision}

Accuracy and precision evaluations were performed on LM1, LM2, and LM3 in 6 replicates in three different days ( $\mathrm{n}$ total $=6 \times 3 \times 3=54$ samples). The required specification range of the product that described in the analytical target profile (ATP) of this present work, was set from 95 to $105 \%$ of the claim label $( \pm 5 \%$ ), with a precision of $2 \%$. If the total error of the manufacturing process was assumed of maximum of $2 \%$, the corrected specification range should be 97 to $103 \%$ ( $\pm 3 \%$ ) [15]. For simplifying, all measured values $\left(Y_{f}\right)$ of LM preparations were calculated as $\%$ to label claim.

According to USP $41<1225>$ [10], accuracy was evaluated by determining the \% recovery (R) of the LM preparations, and evaluating the linearity between the regression curve $Y_{f}$ versus true or nominal concentration $\left(Y_{c}\right)$; the confidence interval $(\mathrm{CI})$ of slope $\left(\mathrm{V} a_{\mathrm{f}}\right)$ and intercept $\left(\mathrm{V} b_{\mathrm{f}}\right)$ were calculated according to the method of Funk et al. $[10,14,16]$. Mean $\mathrm{R}^{-}$was defined as the ratio $\bar{Y} f$ to Yc times $100 \%$. The accuracy method that described by USP $41<1225>$ [10] was identical to the method of Indonesian Pharmacopoeia V [8].

USP $41<1210>$ [11] described the method for estimating accuracy and precision, and combined validation of accuracy and precision. For estimating the accuracy and precision independently, confidence interval (CI) of bias ( $\beta$ ) and standard deviation (U) of the LM preparations were determined.

$$
C l \text { of } \beta=(\bar{Y} f-Y c) \pm t_{1-\alpha: n-1} \times \frac{s}{\sqrt{n}} \ldots
$$

$\beta$ was $100(1-2 \alpha) \%$ two-sided confidence interval of bias, $\mathrm{S}$ was standard deviation, $\mathrm{n}$ was replications, and $t(1-\alpha: n-1)$ was percentile of central t-distribution with area 1- $\alpha$ to the left and $\mathrm{n}$-1 degrees of freedom [11].

$$
U=S \sqrt{\frac{n-1}{x^{2} \alpha: n-1}} \text {. }
$$

where $U$ was an upper (100- $\alpha) \%$ confidence bound for $S, x^{2} \alpha: n-1$ was a percentile of central chi-square distribution with area $\alpha$ to the left and $n$-1 degrees of freedom [11].

Combined validation of accuracy and precision was performed by calculating the prediction interval (PI) and tolerance interval (TI) of Yf. Reportable value ( $\bar{Y} f \pm$ PI or TI) must be included in pre-determined specification range of the ATP.

$$
\text { For prediction interval: } \bar{\gamma} f_{ \pm} t_{(1+P) / 2 ; n-1} \times S \sqrt{1+\frac{1}{n}} \ldots \ldots \ldots
$$

where $t_{(1+P) / 2}$ was percentile of a central $t$-distribution with area $(1+P) / 2$ to the left and $(n-1)$ degrees of freedom [11].

$$
\begin{aligned}
& \text { For tolerance interval: } \overline{\mathrm{Y}} \mathrm{f} \pm \mathrm{K} \times \mathrm{S} \ldots \ldots \ldots(4) \\
& \text { where } \mathrm{K}=\sqrt{\frac{Z^{2}(1+P) / 2}{x^{2} \alpha(n-1} x(n-1)} x\left(1+\frac{1}{n}\right)
\end{aligned}
$$

where $\mathrm{Z}_{(1+P) / 2}^{2}$ was standard normal percentile with area $\alpha$ to the left, $x_{\alpha: n-1}^{2}$ was chi-square percentile distribution with area $\alpha$ to the left and $(n-1)$ degrees of freedom [11].

In order to evaluate the accuracy and precision of bioassays, USP $41<1033>$ [13] described a term of capability process (CP) and out of specification (OOS). This CP approach may be used simply, as a guide for simultaneously evaluation of accuracy and precision of chemical drugs, as described by Kromidas [17]. Evaluation of (OOS) was applied to predict the percentage that may fall outside the specification range.

$$
\begin{array}{r}
\mathrm{Cp}=\frac{\mathrm{USL}-\mathrm{LSL}}{6 S} \ldots \ldots \ldots . \\
\mathrm{Cpk}_{1}=\frac{\mathrm{Y} f-\mathrm{LSL}}{3 \mathrm{~S}}, \mathrm{Cpk}_{2} \frac{\mathrm{USL}-\overline{\mathrm{Y} f}}{3 \mathrm{~S}} .
\end{array}
$$

Where USL was upper specification limit, LSL was lower specification limit.

$$
(\mathrm{OOS})=2 \times \phi(-3 \times C p)
$$

where $\phi$ presents the standard normal cumulative distribution function

All $S$ in equations 1-6 were calculated as intermediate precisions (IP), and standard deviation of the mean (SDM) i.e. the root of the variance of the mean (VM) $[12,15,18]$. 


$$
\mathrm{IP}=\sqrt{\mathrm{S}_{\mathrm{r}^{2}}+\mathrm{S}_{\mathrm{B}^{2}}}
$$

where $\mathrm{Sr}^{2}$ was within condition variance (MS within), Sr was repeatability, $\mathrm{SB}^{2}$ was between condition variance ( Variance $_{\text {Run }}$ ).

$$
\mathrm{S}_{\mathrm{B}}{ }^{2}=\frac{\mathrm{MS}_{\text {between }}-\mathrm{MS}_{\text {within }}}{\mathrm{n} \text { per run }}
$$

$\mathrm{MS}_{\text {between }}$ and $\mathrm{MS}_{\text {within }}$ can be obtained via ANOVA, $\mathrm{n}$ was number of replications for each run.

$$
\mathrm{Sr}=\sqrt{\mathrm{MS}_{\text {within }} \cdots}
$$

$$
\mathrm{VM}=\frac{\text { Variance }_{\mathrm{Run}}}{(\mathrm{N} \text { runs })}+\frac{\text { Variance }_{\text {rep }}}{(\mathrm{N} \text { runs })(\mathrm{n} \text { per run })}
$$

where $\mathrm{N}$ was the number of runs.

\subsubsection{Robustness}

In order to evaluate the robustness of the proposed method, the influence of small variations of three factors of the HPLC's conditions (2.5) on the \% recovery of LM2, were evaluated by using a Plackett-Burman design (Table 2); the three factors were column heater temperature, flow rate, and $\mathrm{pH}$ of the mobile phase. Analysis of effect of those factors was performed according to the method of Gonzales et al. [15,19].

Calculation of IP, SDM, CI, PI, TI, and robustness evaluation were carried out manually or by using Microsoft excel 2010, Quick Calcs - graph Pad [20], statpages.info/tolintvl [21], and selfdeveloped software $\left(\mathrm{VMA}^{\mathrm{R}}\right)$. The validity of the
$\mathrm{VMA}^{\mathrm{R}}$ was evaluated by using Microsoft excel and calculator.

\section{Results and discussion}

\subsection{Method validation}

\subsubsection{Selectivity}

Extract of the blank of the LM preparations showed no peaks. The HPLC chromatogram of the extracts of LM2 showed two peaks of LH and HC. Figure 1 showed the typical HPLC chromatograms of standards, extract of LM2, and blank sample. For confirming the purity of the analyte's peak, RSD of tailing factor (T) and total plate numbers (N) of peaks LH and HC of standards and LM2, were observed by six different wavelengths $(220$, $225,230,235,237,240 \mathrm{~nm}$ ); the RSD were 0.28, $0.94 \%(\mathrm{~T}), 0.17,0.70 \%(\mathrm{~N})$, respectively. This showed that all analyte peaks were relatively pure due to their almost identical $\mathrm{T}$ and $\mathrm{N}$ values [14]. This simple method of peak purity checking can be applied at QC laboratory, especially in the countries in which the facilities of QC laboratories are generally limited.

System suitability was evaluated by six replicate injections of standards solutions of $\mathrm{LH}$ $(1000 \mu \mathrm{g} / \mathrm{mL})$ and $\mathrm{HC}(250 \mu \mathrm{g} / \mathrm{mL}) ; \mathrm{RSD}$ of RTs of $\mathrm{LH}$ and $\mathrm{HC}$ were $0.1 \%(<2 \%)$, whilst for peak areas were $0.6 \%$ and $0.7 \%(<2 \%)$, respectively; tailing factors were mean $\pm \operatorname{RSD}(0.598 \pm 0.2 \%)$

Table 2. Design of experiment for robustness evaluation of LM2

\begin{tabular}{llllll}
\hline Measurement & $\begin{array}{l}\text { Column temperature } \\
\left({ }^{\circ} \mathbf{C}\right)\end{array}$ & $\begin{array}{l}\text { Flow rate } \\
(\mathbf{m l} / \mathbf{m i n})\end{array}$ & $\begin{array}{l}\text { pH of the } \\
\text { mobile phase }\end{array}$ & $\mathbf{R}$ & R of HC (\%) \\
\hline 1 & 26.0 & 0.9 & 6.1 & 103.6 & 101.9 \\
\hline 2 & 26.0 & 1.1 & 5.9 & 99.5 & 97.7 \\
\hline 3 & 24.0 & 1.1 & 6.1 & 105.8 & 98.9 \\
\hline 4 & 24.0 & 0.9 & 5.9 & 100.0 & 98.7 \\
\hline 5 & 26.0 & 0.9 & 6.1 & 99.5 & 96.9 \\
\hline 6 & 26.0 & 1.1 & 5.9 & 103.3 & 100.2 \\
\hline 7 & 24.0 & 1.1 & 6.1 & 102.0 & 99.0 \\
\hline 8 & 24.0 & 0.9 & 5.9 & 103.5 & 101.7 \\
\hline
\end{tabular}

R: recovery 
and $(0.980 \pm 0.6 \%) \quad(<2)$, respectively; total plate numbers were mean \pm RSD $(2647 \pm 0.4 \%)$ and $(64682 \pm 0.7 \%)(>2000)$, respectively. The solutions of standard and LM2's extract were stable for at least $24 \mathrm{~h}$; the results of analysis were $100.29 \pm 0.81 \%$ (standard LH), $100.43 \pm 1.0 \%$ (sample LH), 99.82 $\pm 0.60 \%$ (standard HC) and $100.27 \pm 0.81 \%$ (sample HC). Data (peak areas were compared to fresh solutions) expressed as mean \pm RSD, $n=4$.

\subsubsection{Linearity}

Using this HPLC system, the linearity of LH and HC were achieved in the range of 600.0 to 1500.0 $\mu \mathrm{g} / \mathrm{ml}$ and 160.0 to $360.0 \mu \mathrm{g} / \mathrm{ml}$, respectively. The linear regression line equation for $\mathrm{LH}$ was $\mathrm{Y=}$

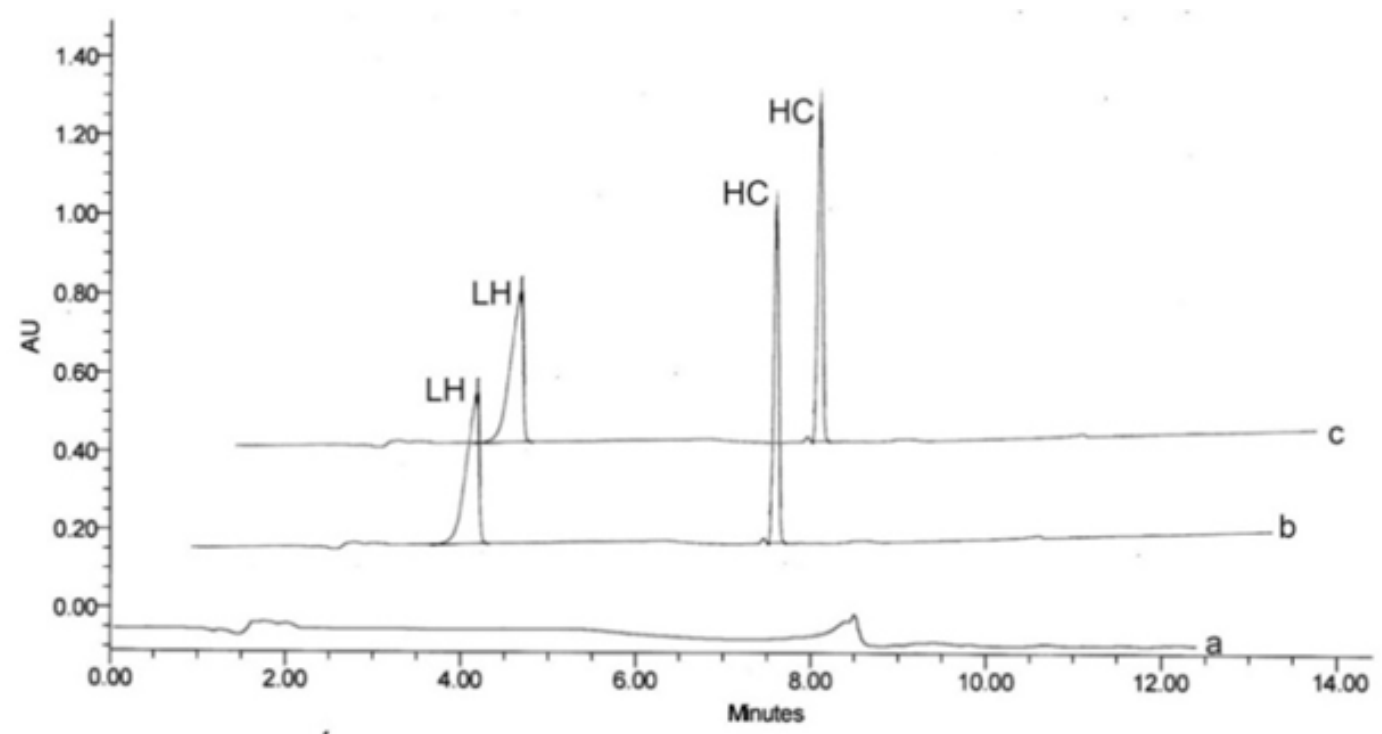

Figure 1. Typical HPLC chromatogram (at $220 \mathrm{~nm}$ ) of extract of the blank sample (a), extract of LM2 suppositories (b), standards solutionof LH and HC (c)

Table 3a. Accuracy evaluation of LH according to the USP $41<1225>$

\begin{tabular}{llll}
\hline Parameters & Day 1 (n = 18) & Day 2 (n= 18) & Day 3 (n= 18) \\
\hline $\mathrm{R}^{-} \pm S D$ & $100.9 \pm 0.70$ & $101.3 \pm 0.95$ & $100.7 \pm 0.36$ \\
Recovery curve's equation & $\mathrm{Y}_{\mathrm{f}}=-1.1972+1.0213 \mathrm{Y}_{\mathrm{c}}$ & $\mathrm{Y}_{\mathrm{f}}=-0.48056+1.0179 \mathrm{Y}_{\mathrm{c}}$ & $\mathrm{Y}_{\mathrm{f}}=-0.34444+1.0100 \mathrm{Y}_{\mathrm{c}}$ \\
$\mathrm{R}$ & 0.9991 & 0.9982 & 0.9998 \\
$\mathrm{~V}$ afa & $-1.1972 \pm 2.3495$ & $-0.48056 \pm 3.2235$ & $-0.34444 \pm 1.1918$ \\
$\mathrm{~V} \mathrm{bfb}$ & $1.0213 \pm 0.023188$ & $1.0179 \pm 0.031814$ & $1.0100 \pm 0.011762$ \\
\hline
\end{tabular}

Table 3b. Accuracy evaluation of HC according to the USP $41<1225>$

\begin{tabular}{llll}
\hline Parameters & Day 1 (n = 18) & Day 2 (n = 18) & Day 3 (n = 18) \\
\hline $\mathrm{R}^{-} \pm \mathrm{SD}$ & $101.1 \pm 0.96$ & $100.0 \pm 0.88$ & $100.0 \pm 0.80$ \\
Recovery curve's equation & $\mathrm{Y}_{\mathrm{f}}=-1.4639+1.0254 \mathrm{Y}_{\mathrm{c}}$ & $\mathrm{Y}_{\mathrm{f}}=-1.1389+1.0117 \mathrm{Y}_{\mathrm{c}}$ & $\mathrm{Y}_{\mathrm{f}}=-1.8389+1.0183 \mathrm{Y}_{\mathrm{c}}$ \\
$\mathrm{R}$ & 0.9983 & 0.9986 & 0.9990 \\
$\mathrm{Va}_{\mathrm{f}}{ }^{\mathrm{a}}$ & $-1.4639 \pm 3.2136$ & $-1.1389 \pm 2.9128$ & $-1.8389 \pm 2.4185$ \\
$\mathrm{Vb}_{\mathrm{f}}^{\mathrm{b}}$ & $1.0254 \pm 0.031716$ & $1.0117 \pm 0.028747$ & $1.0183 \pm 0.023869$ \\
\hline
\end{tabular}

${ }^{a}$ Confidence range of intercept $(\alpha=0.05)$

${ }^{\mathrm{b}}$ Confidence range of slope $(\alpha=0.05)$ 
Table 4. Results of precision of LM preparations

\begin{tabular}{lllllll}
\hline Parameters & \multicolumn{2}{l}{ LM1 $(\mathbf{n = 1 8})$} & \multicolumn{2}{l}{ LM2 $(\mathbf{n = 1 8})$} & \multicolumn{2}{l}{ LM3 $(\mathbf{n}=\mathbf{1 8})$} \\
\cline { 2 - 7 } & LH & HC & LH & HC & LH & HC \\
\hline $\mathrm{Sr}$ & 0.68 & 0.91 & 0.42 & 0.41 & 0.98 & 1.03 \\
$\mathrm{IP}$ & 0.77 & 1.07 & 0.44 & 0.68 & 1.00 & 1.15 \\
$\mathrm{SDM}$ & 0.27 & 0.39 & 0.13 & 0.33 & 0.26 & 0.38 \\
\hline
\end{tabular}

Sr: repeatability

IP: intermediate precision

SDM: standard deviation of the mean

Table 5. Separate evaluations of accuracy and precision according to the USP $41<1210>$ (in $\%$ of label claim)

\begin{tabular}{|c|c|c|c|c|c|}
\hline & & & LM1 (n = 18) & LM2 $(n=18)$ & LM3 $(n=18)$ \\
\hline$\beta^{\mathrm{a}}$ & $\begin{array}{l}\mathrm{LH} \\
\mathrm{HC}\end{array}$ & & $\begin{array}{l}0.6 \\
0.2\end{array}$ & $\begin{array}{l}1.0 \\
-0.1\end{array}$ & $\begin{array}{l}1.3 \\
1.0\end{array}$ \\
\hline \multicolumn{6}{|l|}{$\mathrm{S}^{\mathrm{b}}$} \\
\hline $\begin{array}{l}\text { CI of } \\
\beta^{c}\end{array}$ & $\begin{array}{l}\mathrm{LH} \\
\mathrm{HC}\end{array}$ & $\begin{array}{l}\text { IP } \\
\text { SDM } \\
\text { IP } \\
\text { SDM }\end{array}$ & $\begin{array}{l}0.28 \text { to } 0.92 \\
0.49 \text { to } 0.71 \\
-0.24 \text { to } 0.64 \\
0.04 \text { to } 0.36\end{array}$ & $\begin{array}{l}0.82 \text { to } 1.18 \\
0.95 \text { to } 1.05 \\
-0.38 \text { to } 0.18 \\
-0.24 \text { to } 0.04\end{array}$ & $\begin{array}{l}0.89 \text { to } 1.71 \\
1.19 \text { to } 1.41 \\
0.53 \text { to } 1.47 \\
0.84 \text { to } 1.16\end{array}$ \\
\hline \multirow[t]{3}{*}{$U^{d}$} & $\mathrm{LH}$ & $\begin{array}{l}\text { IP } \\
\text { SDM }\end{array}$ & $\begin{array}{l}1.08 \\
0.38\end{array}$ & $\begin{array}{l}0.62 \\
0.18\end{array}$ & $\begin{array}{l}1.60 \\
0.42\end{array}$ \\
\hline & $\mathrm{HC}$ & IP & 1.50 & 0.95 & 1.61 \\
\hline & & SDM & 0.55 & 0.46 & 0.53 \\
\hline
\end{tabular}

$\mathrm{a}:\left(\bar{Y}^{\mathrm{f}}-\mathrm{Y}^{\mathrm{c}}\right)$

${ }^{\mathrm{b}}: \mathrm{S}$, calculated as IP or SDM

c: CI of $\beta$ were determined by equation $1(\alpha=0.05)$

d: U were by equation $2(\alpha=0.05)$

Table 6. Combination evaluation of accuracy and precision according to the USP $41<1210>$ (in \% of label claim)

\begin{tabular}{|c|c|c|c|c|c|}
\hline & & & LM1 (77.60 - 82.40; $\mathrm{n}=18)$ & LM2 (97-103 ; n=18) & LM3 (116.40 - 123.60 $\left.{ }^{\mathrm{a}} ; \mathrm{n}=18\right)$ \\
\hline $\bar{Y}^{f}$ & $\begin{array}{l}\mathrm{LH} \\
\mathrm{HC} \\
\end{array}$ & & $\begin{array}{l}80.6 \\
80.2 \\
\end{array}$ & $\begin{array}{l}101.0 \\
99.9 \\
\end{array}$ & $\begin{array}{l}121.3 \\
121.0 \\
\end{array}$ \\
\hline $\mathrm{S}^{\mathrm{b}}$ & & & & $\overline{\mathrm{Y} f} \pm \mathrm{PI}$ or TI & \\
\hline $\mathrm{PI}^{\mathrm{c}}$ & $\begin{array}{l}\mathrm{LH} \\
\mathrm{HC}\end{array}$ & $\begin{array}{l}\text { IP } \\
\text { SDM } \\
\text { IP } \\
\text { SDM }\end{array}$ & $\begin{array}{l}79.22 \text { to } 81.98 \\
80.12 \text { to } 81.08 \\
78.29 \text { to } 82.11 \\
79.50 \text { to } 80.90\end{array}$ & $\begin{array}{l}100.21 \text { to } 101.79 \\
100.77 \text { to } 101.23 \\
98.68 \text { to } 101.12 \\
99.31 \text { to } 100.49\end{array}$ & $\begin{array}{l}119.51 \text { to } 123.09 \\
120.84 \text { to } 121.76 \\
118.94 \text { to } 123.06 \\
120.30 \text { to } 121.70\end{array}$ \\
\hline $\mathrm{TI}^{\mathrm{d}}$ & $\begin{array}{l}\mathrm{LH} \\
\mathrm{HC}\end{array}$ & $\begin{array}{l}\text { IP } \\
\text { SDM } \\
\text { IP } \\
\text { SDM }\end{array}$ & $\begin{array}{l}78.78 \text { to } 82.42^{\mathrm{e}} \\
79.96 \text { to } 81.24 \\
77.67 \text { e to } 82.73^{\mathrm{e}} \\
79.28 \text { to } 81.12\end{array}$ & $\begin{array}{l}99.96 \text { to } 102.04 \\
100.69 \text { to } 101.31 \\
98.29 \text { to } 101.51 \\
99.12 \text { to } 100.68\end{array}$ & $\begin{array}{l}118.93 \text { to } 123.66^{\mathrm{e}} \\
120.68 \text { to } 121.92 \\
118.28 \text { to } 123.72^{\mathrm{e}} \\
120.10 \text { to } 121.90\end{array}$ \\
\hline
\end{tabular}

${ }^{\mathrm{a}}$ : Specification range $\left(\mathrm{Y}^{\mathrm{c}} \pm 3 \%\right)$

b: S, calculated as IP or SDM

c: PI (equation 3, $p=90 \%$ )

d: TI (equation $4, p=95 \%$ and $\alpha=0.10$ )

e: Out of specification

$15234 \mathrm{x}+423330, \mathrm{n}=5$, relative process standard deviation Vxo was $0.39 \%, r=0.9999$, calculated testing value $\mathrm{Xp}$ (for $\mathrm{p}=0.05$ ) was $33.6 \mu \mathrm{g} / \mathrm{ml}(<$ $600 \mu \mathrm{g} / \mathrm{ml}$ ), for HC $\mathrm{Y}=54500 \mathrm{x}+1259000$, Vxo 
Table 7. Results of $\mathrm{Cp}, \mathrm{Cpk}$, and OOS of LM

\begin{tabular}{lllllll}
\hline & $\mathbf{S}^{\mathbf{a}}$ & LM & Cp & Cpk1 & Cpk2 & 00S (\%) \\
\hline LH & IP & LM1 & 1.04 & 1.30 & $0.78^{\mathrm{b}}$ & 0.18 \\
& & LM2 & 2.27 & 3.03 & 1.51 & 0.00 \\
& & LM3 & 1.20 & 1.63 & $0.77^{\mathrm{b}}$ & 0.03 \\
& \multirow{4}{*}{ SDM } & LM1 & 2.96 & 3.70 & 2.22 & 0.00 \\
& & LM2 & 7.69 & 10.26 & 5.13 & 0.00 \\
& & LM3 & 4.62 & 6.28 & 2.95 & 0.00 \\
\multirow{4}{*}{ HC } & IP & LM1 & $0.75^{\mathrm{b}}$ & $0.81^{\mathrm{b}}$ & $0.69^{\mathrm{b}}$ & 2.44 \\
& & LM2 & 1.47 & 1.42 & 1.52 & 0.00 \\
& & LM3 & 1.04 & 1.33 & $0.75^{\mathrm{b}}$ & 0.18 \\
& \multirow{3}{*}{ SDM } & LM1 & 2.05 & 2.22 & 1.88 & 0.00 \\
& & LM2 & 3.03 & 2.93 & 3.13 & 0.00 \\
& & LM3 & 3.16 & 4.04 & 2.28 & 0.00 \\
\hline
\end{tabular}

${ }^{\mathrm{a}}: \mathrm{S}$, calculated as IP or SDM

$\mathrm{b}$ : Out of specification

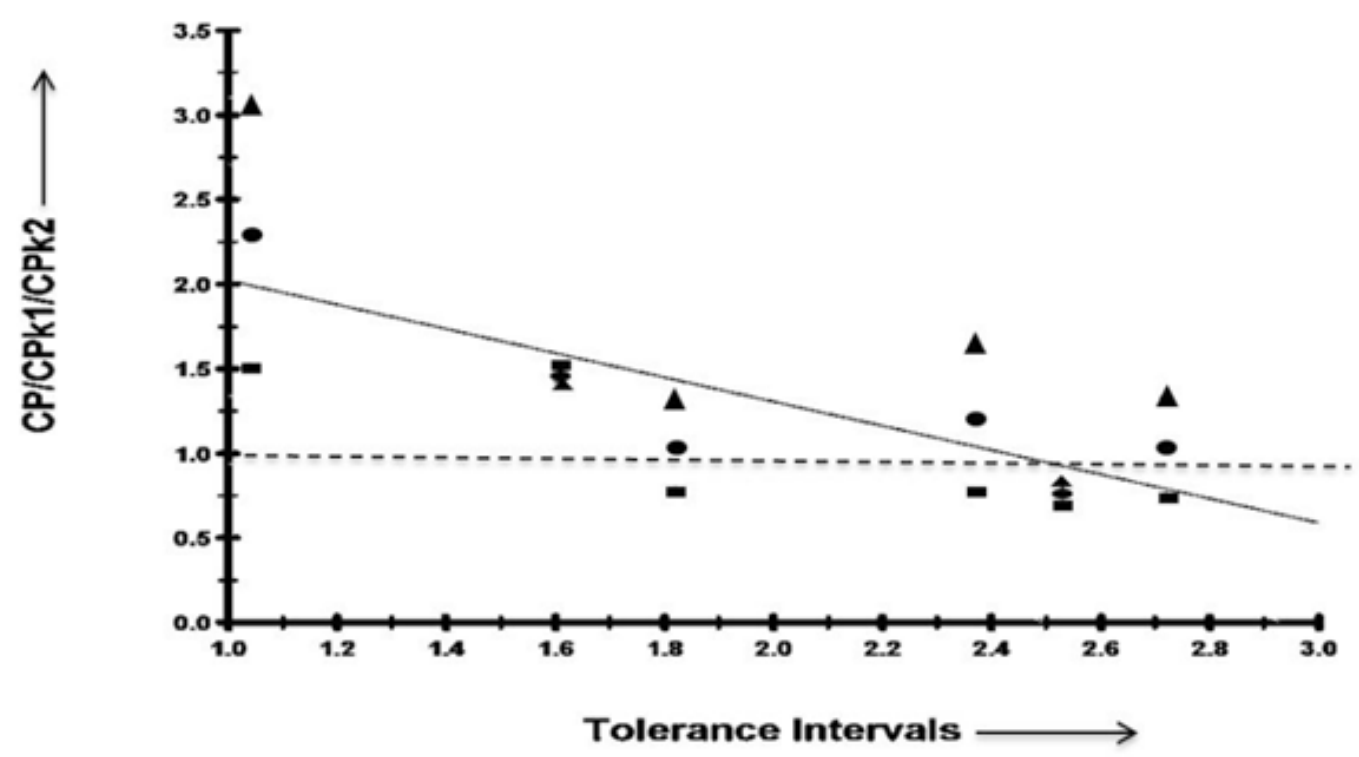

Figure 2. Regression line of $C p / C p k 1 / C p k 2$ Vs of TI, •: Cp, - : CPk1, $\mathbf{\Delta}: C P k 2$

$0.92 \%, r=0.9997, \mathrm{Xp}$ (for $\mathrm{p}=0.05$ ) was $20.8 \mu \mathrm{g} /$ $\mathrm{ml}(<160 \mu \mathrm{g} / \mathrm{ml})$. The residuals were distributed at random around the regression line; neither trend nor unidirectional tendency was found. This linear calibration curve showed variance homogeneity over the whole range. All the linear regression calibration curve parameters used in this present work for accuracy, precision and robustness evaluations showed satisfactory results ( $r>0.99$ ), Xp < lowest level of the calibration standards, Vxo $(<5 \%)[14,16]$.

\subsubsection{Accuracy and precision}

Table 3 demonstrated the high accuracy as revealed by the percentage of $\mathrm{R}^{-}$and $\mathrm{SD}$ of $\mathrm{LH}$ and $\mathrm{HC}$ in three different days $(< \pm 3 \%$ and $<$ $2 \%$, respectively). To prove whether systemic errors did not occur, linear regression of the recovery curves $Y_{f}$ against $Y_{c}$ were evaluated. All $\mathrm{r}$ values of the regression curves showed ( $>0.99$ ), confidence interval of the intercept (Vaf) and slope (Vbf) were not significantly different from zero (0) and one (1), respectively as requested by USP $41<1225>[10,14,16]$.

Table 4 showed that all precision evaluations of LM preparations (repeatability, intermediate precision, and SDM) yielded value less than $2 \%$. $\mathrm{Sr}$ was expressed the precision in one condition 
(day), whereas IP stated precision in different days/conditions. SDM showed the standard deviations of the means in three conditions (day). For the evaluation of precision in different conditions, IP was recommended instead of SDM.

Table 5 showed the results of evaluation of accuracy and precision separately according to USP $41<1210>$ (data in \% of label claim) [11]. For calculating $\mathrm{CI}$ of $\beta$ and $\mathrm{U}$ (equations 1 and 2), IP and SDM were applied respectively, for S. All CI of $\beta$ falls entirely within the specification range of $\pm 3 \%$, and $U$ values were less than $2 \%$.

Table 6 showed the results of combined evaluation of accuracy and precision using the methods of USP $41<1210>$ (data in \% of label claim) [11] all data of $\bar{Y}_{f} \pm$ PI included in the specification range (Yc $\pm 3 \%$ ), if $S$ was calculated as TI, 4 data were out of specification of $\pm 3 \%$, but still included in the specification range of $\pm 5 \%$. These results showed the application of combination accuracy and precision was more sensitive compared to separate evaluation, as showed by Table 3 and 5 .

Data CP and OOS that were presented in the Table 7 confirmed the results of Table 6. If the values of $\mathrm{Cp}$ and $\mathrm{CPK}$ were $>1$, all data of ( $\mathrm{Y} f \pm \mathrm{PI}$ or TI) were inside the specification range. Figure 2 showed the negative correlation between TI and $\mathrm{CP} / \mathrm{CPk}$; regression line equation was $\mathrm{Y}=2.7423$ $-0.71827 \mathrm{X}(\mathrm{r}=-0.86191, \mathrm{r}$ table $=0.5897, \mathrm{n}=18$, $\alpha=0.01$ ). Although some data of $\mathrm{CP}, \mathrm{Cpk}$, and $\bar{Y} f$ \pm TI showed unacceptable results, the OOS were still $<3 \%$. This present work showed the new validation methods of USP $41<1210>$ [11] can be replaced by simpler method of capability process (Cp) as described by USP $41<1033>$ [13] and Kromidas [17] CP/CPk method showed identical results to the new method of USP $41<1210>$ [11].

\subsubsection{Robustness}

The results of \% recovery of robustness evaluations was presented in Table 2. Analysis of effect according to the method of Gonzales et al. $[15,19]$ showed that three described factors (column heater temperature, flow rate, and $\mathrm{pH}$ of the mobile phase) did not affect the results of the $\%$ recovery (data not shown).These data proved that the proposed method was robust.

\section{Conclusions}

This present work showed that the proposed HPLC method is suitable for the simultaneous determination of $\mathrm{LH}$ and $\mathrm{HC}$ in suppositories. This HPLC method is more efficient compared to the densitometric method. The HPLC method is simple, selective, rapid, accurate and robust, and it was validated according to the new method of USP 41. Combined evaluation of accuracy and precision is recommended as a tool for QC, instead of separate determination. It seemed that method of CP/CPk that described by USP $41<1033>$ for bioassays might be applied for chemical drugs as well; this work showed that both methods of USP $41<1210>$ and $<1003>$ yielded identical results. Due to its simplicity, capability process method is recommended as a tool at the QC laboratory of the pharmaceutical industry.

\section{Acknowledgement}

This present work was performed at and fully financially supported by PT. Kimia Farma, Indonesia. The authors are very grateful to $\mathrm{Mr}$. Musrifin (PT. Kimia Farma) for his valuable technical assistances, Ms. Dian Retno Palupi (PT. Bernofarm, Surabaya, Indonesia) for providing some references.

\section{References}

1. https://cekbpom.pom.go.id/index.php/home/ produk/ir1jj9712qup8ct57g88ijqd72/all/ row/10/page/1/order/4/DESC/search/1/ ANTIHEMOROID(16/10/2019).

2. Stojanovic JB, Andjelija M, SlavkoM, Darko I, Mirjana M. Optimation and validation of RP- 
HPLC method for analysis of hydrocortisone acetat and lidocaine in suppositories. Journal of AOAC International. 2010;93(1):102-7.

3. ZivanovicL, ZecevicM, Markovic S, Petrovic S, Ivanovic I. Validation of liquid chromatographic method for analysis of lidocaine hydrochloride, dexamethasone acetate, calcium dobesilate, buthylhydroxyanisol and degradation product hydroquinone in suppositories and ointment. Journal of Chromatography A. 2005;1088(12):182-6.

4. Helboe P, Thomsen M. Single-dose determination of suppositories containing phenylephrine lidocaine and betamethasone valerate by reversed-phase ion-pair liquid chromatography. International Journal of Pharmaceutics. 1979;2(56):317-24.

5. Dołowy M, Kulpińska-Kucia K, Pyka A. Validation of a thin-layer chromatography for the determination of hydrocortisone acetate and lidocaine in a pharmaceutical preparation. The Scientific World Journal. 2014;1-10.

6. Pendela M, KahsayG, Baekelandt I, Van Schepdael A, Adams E. Simultaneous determination of lidocaine hydrochloride, hydrocortisone and nystatin in a pharmaceutical preparation by RPLC. Journal of Pharmaceutical and Biomedical Analysis. 2011;56(3):641-4.

7. Gagliardi L, Amato A, Basili A, Cavazzutti G, Gattavecchia E, Tonelli D. Determination of preservatives in cosmetic products by reversedphase high-performance liquid chromatography. II. Journal of Chromatography A. 1985;325:353-8.

8. Kementerian Kesehatan RI: Farmakope Indonesia Edisi V. Direktorat Jendral Bina Kefarmasian dan Alat Kesehatan. Jakarta: Kemenkes; 2014;776778, 522-523.

9. The United States Pharmacopoeia 41: Official monographs lidocaine hydrochloride, hexachlorophene. United States Pharmacopeia Convention, Rockville, MD. 2018; 2411-2413; 2032-2033.

10. The United States Pharmacopoeia 41:<1225> Validation of Compendial Method. United States
Pharmacopeia Convention, Rockville, MD. 2018; 7665-7671.

11. The United States Pharmacopoeia 41: <1210> Statistical tools for procedure validation. United States Pharmacopeia Convention, Rockville, MD. 2018; 7622-7632.

12. The United States Pharmacopoeia 41: <1010> Analytical data-interpretation and treatment. United States Pharmacopeia Convention, Rockville, MD. 2018; 6706-6720.

13. The United States Pharmacopoeia 41: <1033> Biological assay validation. United States Pharmacopeia Convention, Rockville, MD. 2018:939.

14. Yuwono M, Indrayanto G. Validation method of analysis by using chromatography, In: HG Brittain (Ed.) Profiles of Drugs Substances, Excipients and Related Methodology, Vol. 32, Elsevier Academic Press, San Diego, New York, Boston, London, Sydney, Tokyo, Toronto. 2005; 243-58.

15. Indrayanto G. Validation method of AnalysisUpdated 2011, in H.G. Brittain (Ed.), Indrayanto G. (Contributing Editor). Profiles of drugs substances, Excipients and Related Methodology, Vol. 37, Elsevier Academic Press, San Diego, New York, Boston, London, Sydney, Tokyo, Toronto. 2012; 439-46.

16. Funk W, Dammann V, Donnevert G. Qualitätssicherung in der analytischenchemie, VCH Verlagsgesellschaft $\mathrm{GmbH}$, Weinheim. 1992;10-44:161-200.

17. Kromidas S. Validerung in der Analytik, WileyVCH, Weinheim, 1999;52-106,147-71.

18. Ermer J, Miller J. Method validation in pharmaceutical analysis. A Guide to best practice, Wiley-CVH Verlag GmBH \& Co. KGaA, Weinheim. Pp. 2005:30-35.

19. González AG, Herrador MÁ. A practical guide to analytical method validation, including measurement uncertainty and accuracy profiles. Trends Anal. Chem. 2007;26(3):227-38.

20. https: //www.graphpad.com/quickcalcs / CImean1/(16/10/2019).

21. https://statpages.info/tolintvl (16/10/2019). 